\title{
Research on Information Asymmetry in C2C E-Commerce: Based on the Case of Alibaba
}

\author{
Zhiao Liu ${ }^{1}$ \\ ${ }^{1}$ Management School, University of Liverpool, 2 Vine Street Apartment A69 Liverpool, L7 \\ 7AP, UK \\ *Corresponding author. Email: liuzhiao@yeah.net
}

Keywords: C2C e-commerce, Information asymmetry, Taobao, game analysis

\begin{abstract}
In the network transaction, because the two sides of the transaction are different in time and space and the trading place is a virtual electronic market, information asymmetry is extremely common in $\mathrm{C} 2 \mathrm{C}$ e-commerce; in sim[le terms, in the transaction process of the $\mathrm{C} 2 \mathrm{C}$ e-commerce market, the seller owns all the information about the store and the goods sold, but because the seller pursues its own benefits to maximize the unwillingness to disclose non-positive information of itself or the goods, the information shared by both parties is unevenly distributed, which induces adverse selection and moral hazard problems.

In order to solve these problems and protect the healthy development of the $\mathrm{C} 2 \mathrm{C} \mathrm{e}$-commerce market in China, this paper taking Taobao as the representative model of $\mathrm{C} 2 \mathrm{C}$ e-commerce. Firstly, Taobao.com is taken as an example to analyze the performance, characteristics and influencing factors of information asymmetry between buyers and sellers in C2C e-commerce website. Secondly, a game analysis is carried out for the strategic choices of buyers and sellers under incomplete information. Finally, it puts forward practical policies or suggestions for the analysis results, which helps to reduce the degree of information asymmetry in $\mathrm{C} 2 \mathrm{C}$ e-commerce, so that Taobao and other $\mathrm{C} 2 \mathrm{C}$ e-commerce platforms can achieve better development.
\end{abstract}

\section{INTRODUCTION}

\subsection{Research Background}

The demand for e-commerce by Internet users has rapidly increased, according to the "2017-2018 China E-commerce Development Report", its total transaction volume in 2017 was 29.16 trillion, which is a platform period for China to break through economic development and improve society. The employment situation has made a great contribution.

So far, the most well-known $\mathrm{C} 2 \mathrm{C}$ e-commerce sellers in China are Taobao, eBay, eBay, Yabao, and Paipa. Taobao is the most representative and most successful model of C2C so far. "Statistical Report on Internet Development in China" shows that as of December 2018, the scale of China 's Internet users has reached 829 million, of which the number of mobile Internet users has reached 817 million, and the number of online shopping users in China has reached 610 million, which means that Internet users use shopping The rate is $73.6 \%$; the mobile penetration rate of Taobao has reached $52.5 \%$.

Taobao can become the most representative and successful C2C e-commerce platform model so far, and its many advantages are inseparable. For example: Taobao does not charge store opening costs, which reduces seller costs; Taobao uses the first the three-party payment platform (Alipay) guarantees the credit of both parties; at the same time, the online communication tool "Taobao Want Want" is developed, enabling buyers and sellers to communicate directly, reducing the degree of information asymmetry. But there is no doubt that there are still many shortcomings in Taobao's C2C e-commerce model, such as: the gap between the goods received by the consumer and the seller's description is very large, the logistics and distribution system is not well established, and the actual service of the store does not match the rating, fake and shoddy and so on. These problems stem from the inability of buyers to obtain comprehensive and objective product information. Often, the 
authenticity of the obtained information is not high, which leads to integrity problems for sellers and damage to the interests of buyers.

\subsection{Research Purpose}

In recent years, information asymmetry in $\mathrm{C} 2 \mathrm{C}$ and other e-commerce (such as Taobao) is extremely common. There are many reasons for this, such as sellers being driven by interests, consumers' irrationality, platform supervision and related laws and regulations incomplete, The seller's moral awareness and legal awareness are not strong, etc. These phenomena have brought serious harm to the $\mathrm{C} 2 \mathrm{C}$ e-commerce platform. The harm caused by the information asymmetry problem in $\mathrm{C} 2 \mathrm{C}$ e-commerce can be roughly divided into the following types: First, it directly increases the transaction cost, lengthens the time for the two parties to conclude the transaction, and then leads to the decline of market transaction efficiency and the conversion of platform products. At the same time, the increase in transaction costs will also lead to a reduction in consumers' willingness to buy, which will cause adverse selection problems and hinder the normal development of the market. Second, the purchasing power of buyers is shrinking. The decline in buyer's desire to buy must be manifested in a decrease in buyer's willingness to buy. However, sellers driven by benefits will step up the process of making fake sales, which will cause the entire platform to fall into a vicious circle. Third, the loss of well-known brands. For brand companies, brand image is undoubtedly the most important intangible asset, and customer loyalty is an important guarantee for brand monetization, so when the brand image is damaged, these brands have a great chance to choose to leave the e-commerce platform and so on.[1]

In view of the above, this study takes Taobao (because it is the most representative $\mathrm{C} 2 \mathrm{C}$ e-commerce model) as an example to analyze the performance characteristics, main categories and influencing factors of information asymmetry in $\mathrm{C} 2 \mathrm{C}$. Find out the main causes and existing management measures, and then build a dynamic incomplete information game model based on the above analysis, analyze how to achieve a balanced purchase decision between the two parties in the $\mathrm{C} 2 \mathrm{C}$ e-commerce market, and the conditions needed to achieve the equilibrium. Suggestions to improve the asymmetry of information.

\subsection{Research Significance}

In recent years, information asymmetry in $\mathrm{C} 2 \mathrm{C}$ and other e-commerce (such as Taobao) is extremely common. There are many reasons for this, such as sellers being driven by interests, consumers' irrationality, platform supervision and

\subsubsection{Theoretical Significance}

The characteristics of time and space segmentation and virtualization of network transactions have caused information asymmetry to be very common in $\mathrm{C} 2 \mathrm{C}$ e-commerce. However, George A. Akerlof (1970) has proved that the negative impact of information asymmetry is extremely large, which generally leads to low market operation. Effect, and in severe cases may even lead to market disintegration [2]. Therefore, this paper analyzes the asymmetry of information in the process of C2C e-commerce transactions by theoretical analysis and model analysis to understand the performance, impact, and causes of the problem. At the same time, it summarizes the transaction between the two parties in the $\mathrm{C} 2 \mathrm{C}$ e-commerce market. The conditions needed to achieve a balanced purchase decision are the theoretical significance of this study.

\subsubsection{Practical Significance}

Information asymmetry in $\mathrm{C} 2 \mathrm{C}$ e-commerce transactions is extremely common. Because of the unique nature of online transactions and the nature of merchants' profit-seeking, sellers are reluctant to disclose their private information, so buyers and sellers have a serious grasp of store and product information. Asymmetric distribution. As the largest $\mathrm{C} 2 \mathrm{C}$ e-commerce platform in Asia, Taobao has become a typical representative of China's $\mathrm{C} 2 \mathrm{C}$ e-commerce. The reason why Taobao is so successful proves that it does have many advantages, but we cannot ignore its disadvantages because of its success. Common information asymmetry problems such as: large gaps between physical products 
and descriptions, imperfect logistics and distribution systems, inconsistent actual service and scores in stores, fake and shoddy products, and so on. If the above problems cannot be solved in a timely and effective manner, it will affect the development of related network applications including online payment, cause the development of the e-commerce market to stagnate, slow down the development of the network economy, and ultimately affect the economic development of our country.

This article uses Taobao $\mathrm{C} 2 \mathrm{C}$ as an example to conduct a systematic and in-depth analysis of the extremely common information asymmetry in the transaction process. The purpose is to find the root cause of the problem in order to remedy the situation. Then, by establishing $\mathrm{C} 2 \mathrm{C}$ electronics under incomplete information, The signal game model of buyers and sellers in business transactions, analysis of purchase decisions; finally, based on the analysis results, put forward practical policies or suggestions to solve the problem of information asymmetry, in order to facilitate the better development of Taobao and other e-commerce platforms.

\section{Related Concepts and Theories}

\subsection{Definition of Related Concepts}

\subsubsection{Information Asymmetry Related Concepts}

(1) Connotation of Information Asymmetry

Information asymmetry refers to the uneven distribution of relevant information of the transaction between the two parties in the economic activity, that is, one party has more information than the other. Although the party at the information disadvantage lacks relevant information, it can know the distribution of relevant information and form a certain expectation on the market accordingly.

Yang Min (2009) once defined information asymmetry, saying that it is a phenomenon in which the subjects of market economic activities have different degrees of information; in short, information asymmetry refers to "some participants own but others "Unowned information"; in essence, information asymmetry is caused by market failures and reduced resource allocation efficiency due to different levels of information held by both parties in the market [4].

Scholars such as Zhang Baoyou (2005) pointed out that the asymmetry of information is that in the process of market transactions, one party to the transaction cannot obtain the behavioral information or complete information of the other party, or it is in the hands of the two parties to the transaction due to the high cost of observation and supervision [3].

Chen Jing (2009) published an article pointing out that there are two main points of information asymmetry: one is that the relevant information held by both parties to the transaction is not equal; the other is that both parties to the transaction know their respective positions in information possession [5].

(2) Causes of Information Asymmetry

He Wei (2005) published an article that believes that there are two main reasons for the asymmetry of information: First, objectively speaking, due to the social status and living environment of the parties to the transaction in the market, and the difference in spatial distance, etc., and the relevant information obtained by the parties to the transaction naturally has certain differences, so it can be said that information asymmetry is absolute and unavoidable; secondly, subjectively speaking, in order to maximize their own interests, the parties to the transaction have great probability will use all kinds of legal or illegal means to block the news or even distribute fake news, so that it is in a favorable position [8].

Wang Dong and Yang Xiaoguang (2008) believe that the cause of information asymmetry has the following three points: First, the professional division of society, each person plays a different role in the society, and the information he or she is exposed to is naturally different. As society progresses, this is unavoidable; the second is that the cost of information is different, the time and energy spent by each person to collect and organize information is completely different, and the results obtained are certainly different; the third is from the information transmission process. One of the most common situations in the process is information distortion [9]. 
Su Fangli (2006) summarized four reasons for the asymmetry of information: one is that the social role of each participant is different, and the information that each person first contacts is different; the second is the limitation of personal knowledge. Differences in their own knowledge and literacy, etc., have certain differences in the collection and identification of information. Third, there is a certain cost for participants to search for information. When the cost is greater than the benefits, the participants will give up the search for information. Fourth, they are in the information advantage. Participants in the status will hide some private information due to the pursuit of maximizing their own benefits.

\subsubsection{C2C E-commerce Related Concepts}

\subsubsection{Connotation of E-commerce}

In recent years, e-commerce has penetrated into people's lives with a thunderstorm, but domestic and foreign scholars have different opinions on the concept of e-commerce. So far, there is no clear and clear definition. Here are a few more classic definitions:

The World Trade Organization (WTO) once defined e-commerce in the special report on "e-commerce". A brief summary of e-commerce is the use of network virtual space, that is, through telecommunications networks (not just the Internet, but electronic information technology).

R. Kalakota and B. Winston (1997) define e-commerce from the following four perspectives: (1) communication perspective, e-commerce is the use of network information technology to produce or sell related goods; (2)process automation perspective, e-commerce is just Automated traditional business activities only; (3)from the perspective of service tools, e-commerce is regarded as a special tool, which is unique in that it can reduce service costs while improving its quality; (4)in online perspective, the key is to change the tradition related channels of business activities have been updated. Online channels are more efficient, have a certain de-intermediary role, and have a smaller intermediary effect [12].

Wang Dong and Yang Xiaoguang (2008) believe that: "E-commerce is an electronic transaction that occurs between the two parties based on network information technology. It is also a commercial transaction that involves enterprises and individuals, and the production and transportation of goods." Therefore, there are both connections and differences between e-commerce and traditional business activities.

To sum up, the essence of e-commerce is actually to achieve the optimal combination of social resources and the direct response to personalized needs based on the Internet, the Internet of things, and artificial intelligence and other basic technologies, as well as the automation of traditional business activity workflow, Automation of value-added processes in the business value chain, etc.

\subsubsection{The Basic Model of E-commerce}

\section{(1) Basic Concepts of E-commerce Model}

The business model of e-commerce, referred to as the e-commerce model, is an important dimension for studying e-commerce, and it is also the first starting point for companies to understand the laws of e-commerce operation. Scholars have also defined e-commerce business models from different perspectives. In general, the following are more famous:

Timmers believes that the e-commerce model is a market-based transaction mechanism based on network information technology; this transaction mechanism can reflect the information flow of commodity-related transactions and the process of value creation of commodities during market transactions [33].

Lynda M. APPlegate believes that in the e-commerce model, the independent economic actors are no longer independent, but connected to form a unified whole; meanwhile, the roles of various economic actors (such as manufacturers and sellers) Re-independence, but acting on the entire economic system in the form of a "value network."

Allan Afuah and ChristoPher L. Tucci believe that the e-commerce model is a system for enterprises to quickly and efficiently link the various departments and associated links of business activities through the implementation of information management, and to realize the sharing and exchange of electronic information throughout the entire process. 
In summary, this article summarizes the e-commerce model as an enterprise based on electronic information technologies such as the Internet, the Internet of Things, and artificial intelligence, and realizes the electronicization and virtualization of transaction mechanisms, management mechanisms, and profit models in traditional business activities. Its essence is to build the value creation process of the enterprise in the virtual market of the network.

(2) Basic Model of E-commerce

If the e-commerce model is classified according to transaction objects, it can be divided into the following three types: C2C (Customer to Customer) model, B2B (Business to Business) model, and B2C (Business to Customer) model.

(3) Market Characteristics of C2C E-commerce

In recent years, the $\mathrm{C} 2 \mathrm{C}$ e-commerce market has developed rapidly. According to the methods of traditional economics, based on the degree of market competition, the market structure of e-commerce can be divided into four types in the following table. Through comparative analysis, we can see that the $\mathrm{C} 2 \mathrm{C}$ e-commerce market It is similar to the abstract market in traditional economics where prices are determined by many buyers and sellers and determined by supply and demand. At the same time, it is found that the $\mathrm{C} 2 \mathrm{C}$ e-commerce market has many completely competitive market characteristics.

$\mathrm{C} 2 \mathrm{C}$ e-commerce uses the Internet as a platform for business activities, which undoubtedly lowers the barriers to entry and reduces management costs. At the same time, participants in the market have the opportunity to obtain complete product and demand information. An important feature of perfectly competitive markets is that market participants have access to complete information about the commodity. In the traditional physical market, it is very difficult or even impossible for consumers to obtain complete information about products, but on the e-commerce market, consumers can use related search engines to conduct comprehensive searches for similar products, compare and get information at a relatively low price. Therefore, in comparison, the e-commerce market has a more complete, open and transparent information exchange, but this is only relatively speaking. The exchange of relevant information through the network can not guarantee the information efficiency. Because sellers enter the market, The threshold is very low, resulting in the same product, but the quality is very different.

So the e-commerce market is far from complete information. Only when the seller voluntarily provides the buyer with the opportunity to obtain the complete information of the relevant product, so that the seller occupies more information advantages, and ultimately leads to the problem of asymmetric product quality and product-related description information.

\subsubsection{Refined Bayesian Equalization and Signaling Model}

This article analyzes how to achieve a balanced purchase decision between the two parties in the C2C e-commerce market by establishing a "dynamic incomplete information game model" and the conditions needed to achieve this equilibrium. In view of the characteristics of the two parties in the game, a "signal model" is used [21] Analysis of the possible "Perfect Bayesian Equilibrium".

The "signaling model" is essentially an important application of refined Bayesian equilibrium pioneered by Michael SPence. Michael SPence has used it to analyze how the education level of employees in the labor market transmits information about their own capabilities. In the Michael SPence labor market analysis model, the key assumption is that the decisive factor of the company's production efficiency is the production ability of the company's employees. When the employees' work ability is strong, the company's production efficiency is high, otherwise, the production efficiency is the model also assumes that the information about employees' ability to work is only known to the employees themselves, and the boss of the company does not. However, in this model, education can be used to convey information about this ability. The main reason is that people with high ability can accept knowledge faster, require less education cost, and get a diploma faster. Therefore, although diploma or education level is not the cause of competence, it is a symbol of competence and a signal that can convey the competence of employees. 
It must be noted that in the signal transmission model, the cost of transmitting information is very important for participants. If an action wants to transmit certain information, then the participants who make the action must pay a sufficient price for it, otherwise, The behavior will be imitated by all other types of participants in the market.

\subsection{Summary of Research on Asymmetric E-commerce Information}

\subsubsection{Review of the Causes of E-commerce Information Asymmetry}

Zhang Baoyou et al. (2005) believe that the asymmetry of e-commerce information mainly comes from the following points: First, due to the deepening of the degree of social specialization, the role of people in society is becoming more and more detailed. Because different roles have natural information, gaps, so the asymmetry of information is more common; the second is due to the high cost of searching for information, if the benefits of the act of obtaining information are not enough to cover the cost of the act, the buyer is very likely to abandon the act and cause the two information is asymmetric; the third is because the information itself is uncertain, and the sellers who are in the dominant position of information often hide some real information.

Zhang Lin and Shi Jianjun (2008) thought that it was the asymmetry of e-commerce information caused by the existence of three incentives, namely the transaction environment, virtual attributes and transaction process. Dong Na and Zhou Jin (2009) believed that the asymmetry of e-commerce information caused by the four factors of the virtual nature of online transactions, the factor of the commodity itself, the high cost of information, and the absence of supervision [6].

Qi Yanda and Wang Ying (2009) believe that the asymmetry of e-commerce information is caused by the following three points: the first is that the buyers and sellers are in different spaces; the second is that the sense of integrity is weak, which is usually manifested by the seller in order to obtain greater benefits. Disguise and disseminate false information to induce buyers to make purchases for profit; the third is that since the development of e-commerce has not been less than 20 years, there are still some shortcomings in legal supervision [7].

\subsubsection{Research Review on the Impact of Asymmetric E-commerce Information}

By sorting out related research literatures, it is concluded that their impacts are mainly in the following areas:

Impact on the market. Lai Chunxiu (2009) believes that the information asymmetry problem in the e-commerce market has a more severe impact on the market, and it hinders the development of the market. Unlike the traditional physical market, consumers in the $\mathrm{C} 2 \mathrm{C}$ e-commerce market are not affected by business. A large number of publicity advertisements generate purchase behavior, because the true quality consumers of the products traded in the $\mathrm{C} 2 \mathrm{C}$ e-commerce market can only be known after actual use. This makes it more difficult for sellers to gain the trust of consumers, and it is difficult for merchants to confirm this uncertain factor, which leads to inefficient market operations.

Du Hong (2010) divides the impact of the information symmetry problem in the C2C e-commerce market into two types, which are "the impact of asymmetric business information" and "the impact of asymmetric product quality information" [10], and Hong pointed out that no matter which type of influence consumers are undoubtedly information disadvantaged parties, their rights and interests are difficult to protect. In recent years, e-commerce has developed very rapidly, and various platforms have sprung up. If consumers are dissatisfied or have failed shopping experiences in a certain shopping on an e-commerce platform, then their loyalty to the platform It will be reduced, and there is a great possibility that the platform will be abandoned and other platforms may be chosen, and even online shopping may be abandoned, which means that it is difficult to retain market customers.

Regarding the impact of information asymmetry on merchants in the $\mathrm{C} 2 \mathrm{C}$ e-commerce market, which is different from the traditional physical market, merchants in the e-commerce market cannot increase their own competitiveness by expanding the scale and reducing unit costs. Business life and product life cycles in the business market are shorter, which also leads to the inability of business brand credibility to play an effective role, leading to the failure of merchants selling high-quality goods to gradually withdraw from the market. 
Chia-Hung Sun (2008) used empirical research to analyze the role of merchants' credibility in attracting consumers in the $\mathrm{C} 2 \mathrm{C}$ e-commerce market; he finally found a merchant in online shopping through a Taiwanese online transaction platform as a research object. The reputation's attractiveness to consumers is very large, which shows that online sellers pay more attention to their reputation, but at the same time, because of the attention and focus of consumers, their reputation is more difficult to maintain.

\section{Analysis of C2C Information Asymmetry on TAOBAO}

\subsection{Introduction to Taobao C2C Operation Mode}

Alibaba relied on its rich experience and service capabilities in the B2B e-commerce market, coupled with accurate judgment of the Chinese e-commerce market and detailed understanding of the shopping needs of Chinese netizens, it invested 450 million yuan on May 10, 2003. Founded today's well-known $\mathrm{C} 2 \mathrm{C}$ e-commerce platform, providing an excellent platform for Chinese netizens to shop and trade online.

Obviously, Taobao's e-commerce operation mode is $\mathrm{C} 2 \mathrm{C}$, that is, the e-commerce behavior among consumers. In simple terms, it is to transfer the actual "flea market" to the Internet, to establish a platform for transactions between buyers, and allow buyers to exchange one-on-one with shopping products. The advantage of adopting the $\mathrm{C} 2 \mathrm{C}$ operation mode is that the scope of the transaction is gradually expanding, and the number of participants in the transaction is gradually increasing. The disadvantage is mainly the credit security of network transactions. At present, there are about 20 online platforms using this $\mathrm{C} 2 \mathrm{C}$ auction operation model in China, and Taobao implements a floorless auction mechanism on this basis. This improvement effectively improves transaction efficiency and provides consumers with smooth purchases. channel.

\subsection{Performance of Information Asymmetry in Taobao C2C Transactions}

\subsubsection{Asymmetric Product Quality Information}

In the purchase decision stage, the degree of information asymmetry (buyer's information disadvantage) can be reduced through the efforts of buyers and e-commerce platforms, but it cannot be eliminated.

Taobao's exemption of transaction fees and login fees reduces the entry threshold for transactions, coupled with the fact that virtual stores do not need storefronts, decoration, advertising and other costs have been significantly reduced, so Taobao operators have low entry and exit costs. The low cost of Taobao's entrepreneurship has triggered fierce competition among various sellers in the market. Many sellers will adopt low prices to attract customers, but the quality of goods often shows good and bad. In online transactions, buyers can only use the relevant information provided by the seller to judge the quality of the product. This information includes pictures, text, and videos, but the authenticity of the pictures and text cannot be guaranteed. In fact, sellers often misappropriate the real The pictures of high-quality products or hanging pictures after being processed by PS and so on are visually misleading to buyers, in fact, they are transmitting false product quality information.

As mentioned above, due to the pursuit of maximizing their own interests, the real information disclosed by the sellers is almost always the positive information of the products, and almost no sellers actively disclose the negative information of their products. Therefore, the seller owns all the relevant information of the product, whether it is positive or negative, and the buyer generally can only get the positive information of the product, and rarely get the negative information of the related product, resulting in asymmetric product quality information.

\subsubsection{Asymmetry of Seller Shop Information}

Taobao wants to cultivate more loyal online traders, and then form corporate brand reputation, it must allow relevant users to truly gain benefits in their trading process, so no fees such as transactions and login are charged. Free here can be seen as a different kind of investment, it is mainly used to lower the transaction threshold, while reflecting the principle of fair competition on Taobao. Compared 
with traditional commerce, because of the reduced threshold and the fact that virtual stores do not require storefront storage facilities, the costs of advertising and promotion have been greatly reduced, so Taobao online operators have very low access costs. Low-cost entry barriers have become a major advantage of Taobao.com, as well as many disadvantages. The most typical is that buyers are not able to know the seller's entry and exit in time, which increases the instability of market transactions.

Unlike traditional businesses, the threshold for opening a store on Taobao is very low. Sellers only need to register for membership, and then apply for opening a store and provide personal credentials. Therefore, the authenticity of the information about the store published on Taobao online sellers cannot be verified. , But the buyer can only understand the seller's situation through the pictures, sales records, seller reputation and other information published by the seller on Taobao.com.

\subsection{Impact of Information Asymmetry on Taobao C2C Transactions}

The table below gives simple descriptive statistics for each variable in 13,535 households:

\subsubsection{Impact on Taobao Buyers}

In the $\mathrm{C} 2 \mathrm{C}$ e-commerce market, all the information that buyers can get is provided by the sellers voluntarily, but sellers often provide false information to exaggerate the performance of the products and induce buyers to make purchases based on the principle of maximizing benefits. Although some $\mathrm{C} 2 \mathrm{C}$ e-commerce websites now have regulations on the return of goods, buyers are still relatively disadvantaged in this process. Not only need to negotiate with the seller before returning the product, but also provide relevant proofs. If the negotiation is unsuccessful and a complaint is required, it will face a series of procedures, and it will take a lot of time and money, so obviously after the purchase buyers are also relatively weak.

In recent years, the development of e-commerce has gradually penetrated into people's lives, but it is far from being able to replace traditional markets, and it can only be regarded as a useful supplement to traditional markets. Since the development of e-commerce, the number of platforms has increased dramatically and the types are diverse, and the selectivity and substitutability have become stronger. If a buyer has a bad purchase experience on one platform, he will easily enter other The alternative market even exits the e-commerce market directly, and when there are too few consumers in a market, then this market no longer exists. In short, the asymmetry of information in the $\mathrm{C} 2 \mathrm{C}$ e-commerce market will reduce consumer loyalty, increase the difficulty of retaining customers, and a market without customers also loses its significance.

\subsubsection{Impact on Taobao Sellers}

In the traditional physical market, companies with high-quality goods can generally establish corporate brand reputation in advance and gain consumer trust. It must be pointed out that this is a long-term process; then expanding the production scale and reducing the unit cost of products to shape themselves competitive advantage. In comparison, the life cycle of enterprises and products in the e-commerce market is shorter than that in the traditional physical market. At this time, the possibility of the company successfully establishing the corporate brand reputation in the early stage is reduced, and the corporate brand reputation cannot be used to obtain customer loyalty. Therefore, companies that produce high-quality goods in the e-commerce market cannot simply adopt the method of expanding production scale adopted by enterprises in the traditional market, otherwise they may face a backlog of products. In general, sellers in the e-commerce market face more stress.

\subsection{Taobao C2C E-commerce Information Asymmetry Types}

\subsubsection{Asymmetric Information and Adverse Selection}

It is indicated in advance that the time period during which the problem occurs is the time before the transaction between the buyer and the seller is completed, and the place where the problem occurs is the Taobao virtual shopping market, so in summary, "the a priori information asymmetry means that the buyer and the seller conducting transactions on Taobao. There is a problem of information asymmetry before the transaction is concluded. "The most common situation in ex ante information 
asymmetry is that buyers lack the relevant information and cannot distinguish the quality of the product, which is reflected as the problem of adverse selection.

The problem of information asymmetry in business activities is widespread. The Internet as a trading platform in the $\mathrm{C} 2 \mathrm{C}$ e-commerce market cannot change this problem, and because of the virtual nature of the Internet, information fraud is more common, and buyers cannot determine the quality of a product. Good or bad, can only rely on their own experience, combined with the quality and price of similar goods to make a choice, but in this way, the goods purchased by the buyer may be high-quality goods or inferior goods. Because the quality of the product cannot be touched for the first time, the buyer is required to use the search tool to collect relevant information to know whether the product is a product that they are satisfied with.

In some cases, because buyers know that the quality of the goods they need is relatively low at the time of purchase, they will once again lower the target price when selecting goods; however, the production cost of high-quality goods is lower than that of inferior goods. The production cost is high, so the price is bound to be higher, so in comparison, buyers often choose low-quality low-quality goods, so high-quality goods are gradually eliminated from the market. To put it simply, when a buyer chooses a product, the inner target price will be further reduced due to the low price of similar inferior products in the market. At this time, when the buyer selects the product according to the reduced target price, those high-quality products on Taobao.com. Due to unacceptable low prices, gradually exiting the market, the final result is the "adverse selection problem": Taobao C2C e-commerce market appears "bad coins drive out good coins" phenomenon, the quality of the commodity market capacity gradually shrinks or even disappears. At the same time, the e-commerce market will be occupied by a large number of inferior goods.

\subsubsection{Asymmetry of Postmortem Information and Moral Hazard}

Post-event information asymmetry refers to the fact that the two parties in the transaction form a trustee relationship after determining the product transaction. However, due to the information asymmetry, the seller may damage the buyer in the process of product confirmation transaction, buyer payment and acceptance of the product.

In the process of using Taobao to make purchases, buyers often do not search for ethical product information, so they often decide to purchase goods after communicating with the seller through Taobao Wang Wang. At this time, the principal-agent relationship is established and the seller takes the lead. means. For example: the seller uses the agency right to subprime or use low prices, discounts, etc. to induce. These are all moral hazards caused by asymmetric information of Taobao.

In the $\mathrm{C} 2 \mathrm{C}$ e-commerce market, the funding problem between the two parties to the transaction is also a common problem caused by asymmetric information after the fact. There are two main situations: one is the buyer refuses to receive the goods and the other is the seller refuses to send the money. goods. In Taobao $\mathrm{C} 2 \mathrm{C}$ transactions, the buyer takes the form of payment before the seller delivers the goods, so the risk of the buyer is generally greater than the risk of the seller.

In addition, logistics issues are another manifestation of asymmetry of information after the fact. After shopping on Taobao, the buyer will later entrust the seller to deliver the goods. In order to reduce costs, the seller often accumulates the goods to a certain amount before uniform delivery, but this reduces the efficiency of the buyer in obtaining the goods, especially the short shelf life. Merchandise. When the buyer receives the goods, because of some kind of willingness to request a return, logistics at this time is a problem that bothers the transaction.

\subsection{Reasons for Asymmetry of Taobao C2C E-commerce Information}

\subsubsection{Low-threshold Transactions Enter the Platform}

Compared with traditional commerce, Taobao has greatly reduced the transaction threshold. At the same time, virtual stores do not require storefront storage facilities, and advertising and promotion costs have been greatly reduced. Therefore, Taobao operators have very low access costs. Low-cost entry barriers have become a major advantage of Taobao, but also brought many disadvantages. The presence of too many merchants has caused fierce competition and uneven product quality. Some 
sellers adopt a low price strategy to attract customers, but the products are filled in good time, and the processed product pictures or other sellers' product pictures are hung out, causing visual guidance, passing false information, causing product quality and seller reputation information asymmetry.

\subsubsection{Lack of Seller Reputation}

Due to the virtual nature of online shopping, buyers cannot actually touch the product to get first-hand information, and can only rely on the relevant information provided by the seller to judge the quality of the product. However, sellers often only provide positive information about the product for the purpose of maximizing benefits. Or false information. Buyers use Taobao to make purchases, because the searched product information is incomplete, so they often decide to purchase goods after communicating with the seller through Taobao Want. At this time, the agency relationship is established and the seller occupies a dominant position. Some selling prices often by deceiving the buyer. For example: the seller uses the agency right to subprime or use the low price, discount and other information to induce consumers.

\subsubsection{Lack of Seller Supervision Mechanism}

The degree of information asymmetry is not constant during the entire transaction process. When the buyer receives the product, the degree of information asymmetry is the smallest, because only when the buyer receives the physical product can it be found that the information is inconsistent. At this time, if the buyer chooses to return or exchange the product, the cost is relatively high, so in most cases, the buyer chooses to give up the return or complain.

For example: Taobao stores often use product images for marketing and publicity, and then display related information about the products related to the images. However, consumers cannot know the authenticity of the product information, and the relevant platforms have not supervised it. This kind of situation happened on Taobao is the most those who sell counterfeit and shoddy products, they often use genuine picture information to induce consumers to buy, and damage consumers' trust in genuine brands. However, Taobao has so far not controlled such behavior. In addition, many sellers used credit hype to promote their stores when they first entered Taobao. However, the current technology can't distinguish the authenticity of this information.

\section{Game Analysis of Information Asymmetry in C2C}

In this chapter, a game model is established to analyze how to achieve a balanced purchase decision between the two parties in the $\mathrm{C} 2 \mathrm{C}$ e-commerce market and the conditions needed to achieve this equilibrium. In addition, when trading, the game behavior of the two parties has asymmetric information and is based on The characteristics of sequential actions, therefore, this chapter uses the "dynamic incomplete information game model" to analyze the purchase decision of buyers and sellers in the transaction process by seeking all possible "refined Bayesian (Nash) equilibriums" of the "signaling model".

\subsection{Model Preparation}

\subsubsection{Basic Assumptions}

Based on a summary of a large number of related research literatures, I make the following assumptions around the research purpose of the paper:

1) In the game model of this article, there are only two game subjects, namely the seller (sender) and the buyer (receiver), and both are rational economic persons, both aiming to maximize their own returns;

2) The two players have accurate knowledge of each other's characteristics, strategic space, and payment function;

3) The seller's strategy is "(high price / low price) sell high-quality goods" and "(high / low price) sell low-quality goods", the buyer's strategy is "buy" and "don't buy", and the information on both sides is asymmetric, never know the strategy chosen by the other party before making a decision, that is, the game between the two is a static game; 
4) The prices of related products in the $\mathrm{C} 2 \mathrm{C}$ e-commerce market are uniform, that is, there are only two prices, one is high price $\mathrm{Ph}$, corresponding to high-quality products, and one is low price $\mathrm{Pl}$, corresponding to non-quality products.

\subsubsection{Signal Game Process}

(1) The first is natural selection. The type of "natural" selection seller is assumed to be only "high-quality product type (ST1)" and "inferior product type (ST2)", and the type information is asymmetric, that is, only the seller himself knows his type. The situation, the buyer is unaware of this.

(2) Participants take action after natural selection. Participants take action first. The first is that the seller operator takes action and sends a signal M1 or signal M2 to convey its type information. Among them, M1 indicates that the seller is transmitting the information that it is "selling high-quality goods", and usually adopts a high price strategy to achieve the transmission of the information. Among them, inferior products must bear a certain disguise cost if they want to send the signal; M2 indicates that the seller does not express themselves Is a seller of "Selling Goods."

(3) Because the seller's actions are type-dependent (that is, a type determines a behavior), the buyer will infer the type of the seller according to the signal sent by the seller, and then choose the best according to his own utility optimization. Action, where the best action is represented by A1 when purchased, and the best action is represented by A2 when not purchased.

\subsection{Model Establishment}

\subsubsection{Game Strategy Analysis}

On Taobao, no matter what type of operator is, they can choose two strategies: "selling high-quality goods" and "selling low-quality goods." Sellers can choose to sell at high prices $\mathrm{Ph}$ or low prices $\mathrm{Pl}$ when selling products. Among them, the cost of high-quality products is $\mathrm{C} 1$, the cost of inferior products is $\mathrm{C} 2$, and the obvious $\mathrm{C} 1>\mathrm{C} 2$; in addition, the seller will disguise when he chooses to "sell inferior products at high prices", and the cost of disguise is C3; it is assumed here that "the entire transaction There are only three types of costs in the process. " The cost of camouflage includes not only the cost of replacing packaging, trademarks, etc., but also the risk cost of being found and being held accountable or compensated after the transaction; and the cost of camouflage is the sunk cost, because when the seller is camouflaged and sends a camouflage signal, the cost is already, so the buyer still needs to bear the cost without the buyer.

When sellers sell goods, whether they are high-quality goods or inferior goods, buyers can choose "buy" or "don't buy" two strategies. Among them, the utility of the buyer when purchasing a high-quality product is $\mathrm{V}$, and the utility of the buyer when purchasing a low-quality product is $\mathrm{W}$, and $\mathrm{V}>\mathrm{W}$, and the buyer can perceive $\mathrm{V}$ and $\mathrm{W}$.

The analysis of the purchase decisions of the two players under incomplete information is shown in Table 1 below:

Table 1 Strategy Analysis of both Sides of the Game

\begin{tabular}{|l|l|l|l|}
\hline \multicolumn{1}{|c|}{$\begin{array}{c}\text { Strategies adopted by sellers (first } \\
\text { movers) }\end{array}$} & $\begin{array}{c}\text { Strategies for } \\
\text { buyers (post actors) }\end{array}$ & $\begin{array}{c}\text { Seller } \\
\text { earnings }\end{array}$ & \multicolumn{1}{c|}{$\begin{array}{c}\text { Buyer } \\
\text { earnings }\end{array}$} \\
\hline Selling premium products at high prices & Purchase & Ph-C1 & V-Ph \\
\hline Selling premium products at high prices & Do not purchase & 0 & 0 \\
\hline Selling inferior products at high prices & Purchase & Ph-C3-C2 & W-Ph \\
\hline Selling inferior products at high prices & Do not purchase & $-\mathrm{C} 3$ & 0 \\
\hline Selling quality products at low prices & Purchase & Pl-C1 & V-Pl \\
\hline Selling quality products at low prices & Do not purchase & 0 & 0 \\
\hline Selling inferior products at low prices & Purchase & Pl-C2 & W-Pl \\
\hline Selling inferior products at low prices & Do not purchase & 0 & 0 \\
\hline
\end{tabular}




\subsubsection{Establishing a Game Model and Its Return Matrix}

Based on the above strategy analysis, we can establish the following incomplete information game model on Taobao based on information asymmetry between sellers and buyers.

Through the tree diagram and strategy analysis, we can build a "signal game model" between buyers and sellers when shopping on Taobao. To facilitate analysis, we use buyers to adopt two different strategy classification criteria to classify the utility of both parties. to sum up.

(1) Buyers Adopt Purchasing Strategy A1

According to the table 4-1 "Strategy Analysis of the Two Parties in the Game", only under the four conditions of (1), (3), (5) and (7), buyers will adopt the purchasing strategy (A1), as shown in Table 2 .

From Table 2, it can be clearly seen that when the buyer adopts a purchasing strategy, the profit matrix of the buyer and seller is shown in Table 3.

(2) The Buyer Adopts No Purchase Strategy A2

According to the table 4-1 "Strategy Analysis for Both Parties in the Game", only under the four conditions of (2), (4), (6) and (8), buyers will adopt the non-purchase strategy (A2), as shown in Table 4.

From Table 4-4, it can be clearly seen that when the buyer adopts the non-purchase strategy, the profit matrix of the buyer and seller is shown in Table 5 .

Table 2 Strategy Analysis of both Sides of the Game When the Buyer Purchases

\begin{tabular}{|c|c|c|c|}
\hline $\begin{array}{c}\text { Strategies adopted by sellers (first } \\
\text { movers) }\end{array}$ & $\begin{array}{c}\text { Strategies for } \\
\text { buyers (post actors) }\end{array}$ & $\begin{array}{c}\text { Seller } \\
\text { earnings }\end{array}$ & $\begin{array}{c}\text { Buyer } \\
\text { earnings }\end{array}$ \\
\hline $\begin{array}{c}\text { Selling high-quality products at high prices } \\
\text { (ST1 merchant sends signal M1) }\end{array}$ & Purchase & Ph-C1 & $\mathrm{V}-\mathrm{Ph}$ \\
\hline $\begin{array}{c}\text { Selling inferior products at high prices } \\
\text { (ST2 merchant sends signal M1) }\end{array}$ & Purchase & $\mathrm{Ph}-\mathrm{C} 3-\mathrm{C} 2$ & $\mathrm{~W}-\mathrm{Ph}$ \\
\hline $\begin{array}{c}\text { Selling quality products at low prices } \\
\text { (signal M2 from ST1 merchants) }\end{array}$ & Purchase & $\mathrm{Pl}-\mathrm{C} 2$ & $\mathrm{~W}-\mathrm{Pl}$ \\
\hline $\begin{array}{c}\text { Selling inferior products at low prices } \\
\text { (ST2 merchant sends signal M2) }\end{array}$ & Purchase & $\mathrm{Pl}-\mathrm{C} 1$ & $\mathrm{~V}-\mathrm{Pl}$ \\
\hline
\end{tabular}

Table 3 When the buyer adopts the purchase (A1) strategy, buyer and seller's income matrix

\begin{tabular}{|c|c|c|c|}
\hline & \multicolumn{2}{|c|}{ Buyer (Purchase) } \\
\hline & & Signal M1 & Signal M2 \\
\hline \multirow{2}{*}{ Seller (signal) } & ST1 & $(\mathrm{Ph}-\mathrm{C} 1, \mathrm{~V}-\mathrm{Ph})$ & (Pl-C1, V-Pl) \\
\hline & ST2 & $(\mathrm{Ph}-\mathrm{C} 3-\mathrm{C} 2, \mathrm{~W}-\mathrm{Ph})$ & (Pl-C2, W-Pl) \\
\hline
\end{tabular}

Table 4 Analysis of the Strategies of both Players when the Buyer Does Not Buy

\begin{tabular}{|c|c|c|c|}
\hline $\begin{array}{c}\text { Strategies adopted by sellers (first } \\
\text { movers) }\end{array}$ & $\begin{array}{c}\text { Strategies for } \\
\text { buyers (post actors) }\end{array}$ & $\begin{array}{c}\text { Seller } \\
\text { earnings }\end{array}$ & $\begin{array}{c}\text { Buyer } \\
\text { earnings }\end{array}$ \\
\hline $\begin{array}{c}\text { Selling high-quality products at high prices } \\
\text { (ST1 merchant sends signal M1) }\end{array}$ & Do not purchase & 0 & 0 \\
\hline $\begin{array}{c}\text { Selling inferior products at high prices } \\
\text { (ST2 merchant sends signal M1) }\end{array}$ & Do not purchase & $-\mathrm{C} 3$ & 0 \\
\hline $\begin{array}{c}\text { Selling quality products at low prices } \\
\text { (signal M2 from ST1 merchants) }\end{array}$ & Do not purchase & 0 & 0 \\
\hline $\begin{array}{c}\text { Selling inferior products at low prices } \\
\text { (ST2 merchant sends signal M2) }\end{array}$ & Do not purchase & 0 & 0 \\
\hline
\end{tabular}

Table 5 When Buyer Adopts the Non-buying (A2) Strategy, Buyer and Seller's Income Matrix

\begin{tabular}{|l|l|c|c|}
\hline \multicolumn{2}{|c|}{} & \multicolumn{2}{c|}{ Buyer (Purchase) } \\
\cline { 3 - 4 } \multicolumn{2}{|c|}{} & Signal M1 & ST1 \\
\hline \multirow{2}{*}{ Seller (signal) } & ST1 & Seller (signal) & ST2 \\
\cline { 2 - 4 } & ST2 & & \\
\hline
\end{tabular}




\subsection{Model Analysis and Solution}

\subsubsection{Separation Equilibrium}

When the merchants in the market send their true type signals with probability 1 , that is, when the seller of high-quality products ST1 sends a signal M1 and the seller of poor-quality products ST2 sends a signal M2, the buyer can directly judge based on the received signal. According to the type of seller, the market mechanism operates normally at this time, and the separation and equilibrium of the signal transmission model can be achieved. The specific analysis is as follows:

(1) Buyer Perspective

When the seller sends the M1 signal, it can be known that the type of the seller at this time is a high-quality product ST2. At this time, the expectations obtained by the buyer using the A1 and A2 strategies are $\mathrm{V}-\mathrm{Ph}$ and 0 , respectively. Knowing that $\mathrm{V}-\mathrm{Ph}>0$, the purchase is taken. The expectation obtained by the strategy is greater than that obtained when the non-purchase strategy is adopted; when the seller sends a signal M2, it indicates that it is a low-quality product ST2. At this time, the buyer's expectations of adopting the A1 and A2 strategies are W-P1 and 0, respectively. It is known that $\mathrm{W}-\mathrm{Pl}>0$, that is, the expectation obtained by adopting a purchase strategy is greater than the expectation obtained by adopting a non-purchase strategy.

In summary, when the seller will definitely (probability 1) indicate his true type, the best strategy for consumers is the purchase strategy.

(2) Seller's Perspective

Assume that the strategy chosen by the buyer at this time is the buying strategy (that is, the probability that the consumer purchases the product is 1). Considering the choice of the seller's profit maximization strategy, the profit situation is shown in Table 4-3 above.

When the buyer will definitely buy the goods, the gains that the ST1 type seller sends the signal $\mathrm{M} 1$ and the signal M2 are $\mathrm{Ph}-\mathrm{C} 1$ and $\mathrm{Pl}-\mathrm{C} 1$, respectively. Known that $\mathrm{Ph}-\mathrm{C} 1>\mathrm{Pl}-\mathrm{C} 1$, so the ST1 type seller is the most The best strategy is to send the M1 signal; the gains that ST2 type sellers can send to the signals $\mathrm{M} 1$ and $\mathrm{M} 2$ are $\mathrm{Ph}-\mathrm{C} 3-\mathrm{C} 2$ and $\mathrm{Pl}-\mathrm{C} 2$. At this time, the seller's behavioral decision cannot be directly obtained. The key lies in $\mathrm{Ph}-\mathrm{C} 3$. -The relative sizes of $\mathrm{C} 2$ and $\mathrm{Pl}-\mathrm{C} 2$. When $\mathrm{Ph}-\mathrm{C} 3-\mathrm{C} 2$ $<\mathrm{Pl}-\mathrm{C} 2$, that is, the seller's disguise cost is greater than the difference between the disguise revenue price, the seller's decision is to send a signal M2, and the separation of the transfer model is achieved balanced.

\subsubsection{Mixed Equalization}

When the market is in a mixed equilibrium situation, different types of merchants in the market all send the same signal, resulting in the buyer cannot directly determine the type of the operator based on the received signal, and can only perform a priori based on the signal sent by the operator Inferred, assuming the prior probability is $(\mathrm{P}, 1-\mathrm{P})$, that is, the probability that the signal is true is $\mathrm{P}$, and the probability that the signal is not true is $1-\mathrm{P}$.

(1) Buyer Perspective

If the seller sends a signal M2, then the buyer's A1 and A2 strategies will earn P (V-Pl) + (1-P) $(\mathrm{W}-\mathrm{Pl})$ and 0 , respectively. Known $\mathrm{P}(\mathrm{V}-\mathrm{Pl})+(1-\mathrm{P})(\mathrm{W}-\mathrm{Pl})>0$, so at this time, the rational buyer should adopt the strategy as the buying strategy; if the seller sends a signal M1, then the buyer adopts the strategy of $\mathrm{A} 1$ and $\mathrm{A} 2$ The returns are $\mathrm{P}(\mathrm{V}-\mathrm{Ph})+(1-\mathrm{P})(\mathrm{W}-\mathrm{Ph}), 0$, and the buyer's decision depends on the relative size of the return. At this time, it is known that $\mathrm{V}-\mathrm{Ph}>0>\mathrm{W}-\mathrm{Ph}$ relationship, so The relative size of $\mathrm{P}(\mathrm{V}-\mathrm{Ph})+(1-\mathrm{P})(\mathrm{W}-\mathrm{Ph})$ and 0 is determined by the size of $\mathrm{P}$ :

When $\mathrm{P}$ is large and 1-P is small, $\mathrm{P}(\mathrm{V}-\mathrm{Ph})+(1-\mathrm{P})(\mathrm{W}-\mathrm{Ph})<0$. At this time, consumers should preferably adopt a purchasing strategy; when $\mathrm{P}$ is small and $1-\mathrm{P}$ is larger when $\mathrm{P}(\mathrm{V}-\mathrm{Ph})+(1-\mathrm{P})$ $(\mathrm{W}-\mathrm{Ph})>0$. At this time, the best action for consumers is to adopt a no-buy strategy.

(2) Seller's Perspective

1) Assuming the Buyer's Action Choice is to Adopt a No-buy Strategy,

At this time, the high-quality product type ST1 sends the signal M1 or the signal M2 to obtain the same expected return, which is 0; while the low-quality product type ST2 merchant sends the signal 
$\mathrm{M} 1$, the expected return is $-\mathrm{C} 3$, and it needs to pay the camouflage cost. When the signal M2 is sent, the expected return is 0 . Obviously, $0>-\mathrm{C} 3$, so the merchant of the poor quality ST2 type will choose to send the signal M2 to indicate his true type, and eventually the hybrid equilibrium is not achieved.

2) Assume that the Buyer's Action is to Adopt a Buying Strategy

At this time, the expected return obtained by the ST1 type merchant when sending the signal M1 is $\mathrm{Ph}-\mathrm{C} 1$, and the expected return obtained when sending the signal M2 is $\mathrm{Pl}-\mathrm{C} 1$. Obviously, $\mathrm{Ph}-\mathrm{C} 1>$ $\mathrm{Pl}-\mathrm{C} 1$, so at this time, the quality product ST1 type The merchant chooses to send a signal M1 to the consumer to indicate his true type; while the merchant of the inferior product ST2 type sends the signal M1 to get the expected return of $\mathrm{Ph}-\mathrm{C} 3-\mathrm{C} 2$, and the signal M2 to get the expected return of $\mathrm{Pl}-\mathrm{C} 2$. In this case, if Ph-C3-C2> Pl-C2 is satisfied, the homogeneous equilibrium can be achieved, that is, when the cost of disguising the camouflage is less than the difference between the price and the price of the disguise, the ST2 type of inferior products tends to disguise themselves It is a ST1 type merchant, which induces consumers to make purchases. At this time, the problem of asymmetric information between buyers and sellers is serious.

\subsubsection{Quasi-separated Equilibrium}

At the time of quasi-separation equilibrium, the probability of a ST1 type merchant to indicate its true type is 1 , and the probability of camouflage is 0; while the ST2 type of business indicates its probability to be 1-a, and the probability of camouflage is a. Therefore, once the buyer receives the signal M2, it can directly determine its type as ST2; but when the buyer receives the signal M1, since the two types of merchants, ST1 and ST2, will send out the signal M1, the probability is 1 and a, so At this time, the buyer cannot directly determine the true type of the seller, and thus cannot determine the quality of the goods sold by the seller.

\section{(1) Buyer Perspective}

If the seller 's true identity is the ST1 type of high-quality products, when the buyer can directly determine that his true type is ST1, he will adopt strategy A1 to obtain a profit $\mathrm{V}-\mathrm{Ph}>0$; if the seller is of the ST2 type, it sends signals M1 and The probability of the signal M2 is a, 1-a; at this time, the buyer adopts the strategies $\mathrm{A} 1$ and $\mathrm{A} 2$, and the gains obtained are a (W-Ph) $+(1-\mathrm{a})(\mathrm{W}-\mathrm{Pl}), 0$, at this time Only if a $(\mathrm{W}-\mathrm{Ph})+(1-\mathrm{a})(\mathrm{W}-\mathrm{Pl})>0$, the buyer will choose to buy.

(2) Seller's Perspective

ST1 type merchants will definitely indicate their true type, and the decision of inferior products ST2 type sellers depends on the relative size of the benefits that can be obtained after the two decisions are executed, specifically: as long as the signal M1 brings. When the income Ph-C3-C2 is greater than the income P1-C2 brought by the signal M2, the ST2 type seller will choose to disguise to make a profit; only when the signal M1 hides its true type, the profit will not be greater than send the signal M2 to indicate the income brought by the real type. When the condition $\mathrm{Ph}-\mathrm{C} 3-\mathrm{C} 2 \leq \mathrm{Pl}-\mathrm{C} 2$ is satisfied, that is, when the additional income that cannot be obtained by disguising, the ST2 type merchant will stop disguising, misleading the consumption.

Through the analysis of the signal game model of the buyers and sellers, we can roughly understand how to achieve a balanced purchase decision between the two parties in the C2C e-commerce market and the conditions needed to achieve the equilibrium. There are two main situations: (1)there are mixed equalization and quasi-separated equalization. Inferior products ST2 type merchants will all send a signal M1 in order to maximize their own revenue to induce consumers to make purchases. At this time, consumers cannot determine the true type of the merchant, resulting in consumers being unable to make correct purchase decisions; (2)there is a separation equilibrium. When the inferior product ST2 type merchant sends the signal M1, the disguise cost is greater than the price difference (the expected return of the merchant), that is, $\mathrm{C} 3>\mathrm{Ph}-\mathrm{Pl}$, the buyer and the seller achieve a separation equilibrium, and it is only beneficial when the seller indicates his true type. It is graphable, so at this time the sellers are willing to send real signals, and the buyers can also accurately distinguish the types of sellers, so that they can choose the actions that are most beneficial to them. In this case, the market performance is also the best. 


\section{Improvement Strategies and Suggestions Conclusions}

By analyzing the signal game model of the buyer and seller in the $\mathrm{C} 2 \mathrm{C}$ e-commerce market in the previous chapter, we fully realized the impact of information asymmetry on the efficiency of the e-commerce market, so this chapter proposes some solutions to reduce the information asymmetry degree to provide decision-making reference for the further healthy development of the $\mathrm{C} 2 \mathrm{C}$ e-commerce market.

\subsection{Recommendations for C2C E-commerce Platforms}

In daily supervision, the $\mathrm{C} 2 \mathrm{C}$ e-commerce platform should be the most direct and effective supervisor.

\subsubsection{Improve the Seller's Credit Evaluation Mechanism}

In the $\mathrm{C} 2 \mathrm{C}$ e-commerce market, the seller owns all the information of the product, and the information received by the consumer in the information disadvantaged position is mostly published by the merchant itself, so the authenticity of the information is difficult to distinguish, so when consumers make a purchase decision, and it is necessary to refer to the evaluation of the store and the goods by others. Although most shopping platforms have established credit evaluation mechanisms for shops and goods sold, there is no sound supervision mechanism and a mature market environment, leading to credit evaluation mechanisms.

In the simplest case, in order to improve the credit rating of a store or the praise of a certain product, the merchants on Taobao.com often "employ people to pay bills" or carry out activities such as "praise cashback" by consumers, and even threaten consumption. The abolition of the negative events of the bad reviews disrupted the market order and harmed the rights and interests of consumers. Therefore, for the healthy development of online shopping, it is necessary to improve and optimize the existing credit evaluation mechanism and obtain a true and credible credit evaluation in order to increase the camouflage cost of merchants selling inferior products and help consumers identify information.

\subsubsection{Broaden the Communication Channels Between Consumers}

The commodities traded in the $\mathrm{C} 2 \mathrm{C}$ e-commerce market are mostly empirical products. Consumers can only know the true quality of the goods after they have been used. Therefore, only consumers have the most say in the quality of the goods. Then, consumers need to be broadened. The channels of communication between consumers enable consumers to obtain sufficient information to understand the true quality of the product before making a purchase, and help consumers reduce their information disadvantages to the greatest extent.

To strengthen information exchange between consumers, in addition to the most important to broaden communication channels, it is also necessary to establish and maintain information exchange forums for related products. At the same time, the forums need to be divided into different topics so that everyone can communicate more efficiently. Search function, consumers can use this function to quickly and easily collect all evaluations of a certain product sold by a certain merchant; in addition, it is also necessary to provide an online such as Taobao Wang Wang for consumers real-time communication tools, so that consumers can communicate in a timely and effective way to get more product information.

\subsubsection{Improve Market Access Requirements}

The direct consequence of the low entry threshold of $\mathrm{C} 2 \mathrm{C}$ e-commerce is the good and bad of the quality of the products in the market, the vagueness of the seller's information, etc. These are reflected in the asymmetry of transaction information between the buyer and the seller. Taking Taobao as an example, most sellers only need to apply to become a member, then apply to open a store, and then submit relevant documents such as personal credentials. There are no relevant restrictions on the size and credit of the seller. The low requirements for entry barriers bring benefits to consumers. At the same time, it also deepens the degree of information asymmetry in the $\mathrm{C} 2 \mathrm{C}$ market.

Therefore, the government and relevant platforms need to cooperate with each other to improve the access requirements of the $\mathrm{C} 2 \mathrm{C}$ e-commerce market, strictly control the credibility of the resident 
merchants, and timely remove the unreliable merchants from the market to ensure a harmonious and friendly shopping environment in the market. When a seller wants to open a store on a platform, the platform must strictly perform the real-name authentication of the merchant and require the merchant to provide relevant information such as business licenses; at the same time, relevant government departments and related platforms must verify the authenticity of the relevant information. Once the existence of false information is found, immediately take relevant measures to restrict its entry into the market, thereby blocking non-compliant merchants, improving the reputation of sellers, and ensuring good order in the market.

\subsection{Targeting Information Search: Introducing Information Intermediaries}

Introduce information intermediaries in the $\mathrm{C} 2 \mathrm{C}$ e-commerce market to reduce the cost of collecting relevant information about the products that consumers want to buy, and reduce the degree of information asymmetry between buyers and sellers, so as to avoid the emergence of bad coins to drive out good coins due to the problem of adverse selection to improve the operational efficiency of the $\mathrm{C} 2 \mathrm{C}$ e-commerce market. It should be noted that after the introduction of the information intermediary, in order to ensure that the information provided by the information intermediary is authentic and reliable, the information intermediary must be required to conduct a long-term and timely investigation of the quality of the relevant products on the $\mathrm{C} 2 \mathrm{C}$ e-commerce website. Carry out fair assessment and screening of the quality of its products, and provide timely feedback to consumers.

\subsection{Recommendations for Government Regulators}

For government departments, it is a long-term task to reduce the degree of information asymmetry in the $\mathrm{C} 2 \mathrm{C}$ e-commerce market and improve the efficiency of market operations, and the specific measures are.

(I) Establish and Iprove e-commerce market laws and regulations, and improve the market supervision system.

Like the traditional physical market, the e-commerce market can only develop healthily with the help of sound laws and regulations. For government departments, vigorously rectifying and standardizing the economic order of e-commerce is a long-term task, and it is imperative to establish sound laws and regulations applicable to the e-commerce market and improve the market surveillance system. The perfect market supervision system requires relevant supervisory departments to implement specific supervision work to each administrative unit and department, and strictly requires each department unit to perform its duties. At the same time, improving the market supervision system requires relevant supervisory departments to establish relevant reward and punishment systems to mobilize various Similar social forces are conducting mutual supervision to gradually improve the laws and regulations related to the electronic market.

The key to the functioning of relevant laws and regulations in the e-commerce market is that the relevant regulatory authorities must strictly abide by the relevant laws and regulations, enforce laws in accordance with the law, strengthen law enforcement, and strengthen law enforcement. At the same time, for some manufacturers that produce or sell inferior products or even fake and inferior products, they need to properly strengthen the punishment.

(2) Establishing a "C2C E-commerce Supervision and Management Institution".

$\mathrm{C} 2 \mathrm{C}$ e-commerce is essentially the same as traditional business activities. It also requires specialized supervision and management agencies to restrict it. Especially in recent years, the market economic value created by $\mathrm{C} 2 \mathrm{C}$ e-commerce has become higher and higher, as a new economic growth point for the country. In order to ensure the efficiency of the market operation, a special C2C e-commerce market supervision and management institution should also be established. The service target of this institution is different from traditional industrial and commercial departments, mainly individuals or enterprises engaged in business activities in the $\mathrm{C} 2 \mathrm{C}$ e-commerce market. 
In addition to the similar responsibilities of the traditional industrial and commercial departments, $\mathrm{C} 2 \mathrm{C}$ e-commerce supervision agencies also specialize in online transactions. In summary, their basic responsibilities are: merchant $\mathrm{C} 2 \mathrm{C}$ e-commerce market entry and exit qualification approval, transaction identity verification, and merchant transaction credit. Evaluation and long-term cumulative scoring, conflict handling during the transaction process, acceptance of related complaints, etc. The establishment of a specialized $\mathrm{C} 2 \mathrm{C}$ e-commerce market supervision and management agency can effectively restrict the current chaotic situation of e-commerce, purify the market environment, and improve the efficiency of market operations.

\section{References}

[1] Wang Xuemei. Reflections on the "Lemon" Problem in the E-commerce Market [J]. Journal of Langfang Teachers College (Natural Science Edition), 2008, 8 (4): 89-90.

[2] George A. Akerlof. "Lemon" Market: Uncertainty in Quality and Market Mechanisms [J]. Economic Review, 2001, (6): 1-8.

[3] Zhang Baoyou, Lu Xufen, Tang Yibing. Research on E-commerce and Information Asymmetry [J]. Northern Economy, 2005, (10).

[4] Yang Min. Information Asymmetry in E-commerce [J]. Gansu Science and Technology, 2009, 25 (9): 69-71.

[5] Chen Jing. Analysis of Resource Information Disclosure under Information Asymmetry [J]. Modern Information, 2009, 29 (4): 7-9.

[6] Dong Na, Zhou Jin. Discussion on Information Asymmetry in E-commerce [J]. Journal of Huainan Vocational and Technical College, 2009, 9 (1).

[7] Yan Yanda, Wang Ying. Analysis and countermeasures of information asymmetry in e-commerce [J]. Journal of Tonghua Teachers College, 2009, 30 (10): 82-83.

[8] He Wei. Research on Information Asymmetry Based on Network Environment [J]. Commercial Research, 2005 (15): 192-193.

[9] Wang Dong, Yang Xiaoguang. Impact of Information Asymmetry on the Development of E-commerce in China [J]. Agriculture and Technology, 2008, 28 (3): 119-124.

[10] Du Hong. Game analysis of information asymmetry in $\mathrm{C} 2 \mathrm{C}$ e-commerce transactions [J]. Enterprise Economy, 2010 (6): 40-42.

[11] Dong Gang. Research on the Factors Affecting Consumer Trust in C2C E-commerce [D]. Jilin University, 2008.

[12] Whinston A B, Choi S Y, Stahl D O. Economics of Electronic Commerce [M]. Electronics Industry Press, 2000: 25-26, 115-117.

[13] Xun Meili, Cao Danqiu. Analysis on Information Asymmetry in "C2C" E-commerce: Taking Taobao as an Example [J]. Economic Forum, 2016 (7): 62-64.

[14] Jiang Xinxia. Research on counterfeit and shoddy behaviors of Taobao.com based on game theory and governance strategies [D]. South China University of Technology, 2013.

[15] Zhang Lin, Shi Jianjun. Research on countermeasures of information asymmetry and e-commerce risk control [J]. Modern Management Science, 2008 (1): 3-5.

[16] Jin Huan. Analysis and improvement of information asymmetry in Taobao C2C e-commerce [D]. Jilin University, 2011. 
[17] Wang Yifeng, Guo Jinli. Analysis of Information Asymmetry in C2C E-commerce Market_-Taobao as an Example [J]. Modern Enterprises, 2015 (12).

[18] Zhao Chenxin. Research on C2C Operation Mode of Internet E-Commerce-Taobao Website as an Example [J]. China Market, 2017 (15).

[19] Zhao Ran. Research on the business model of C2C third-party e-commerce platform [D]. Capital University of Economics and Business, 2009.

[20] Song Tingting. Game Analysis of Integrity in E-commerce Transactions [J]. Modernization of Shopping Malls, 2011 (14): 74-74. 